\title{
If they could talk to the animals...
}

Too many conservation

projects are failing

because of ignorance about the behaviour of endangered species. This is why the natural world needs ethologists, says Jonathan Knight. the uninitiated, wildlife conservation and animal behaviour seem like two sides of the same coin. Conditioned by television wildlife documentaries featuring singing whales and leaping antelope, we imagine that conservation biologists are well versed in ethology, the scientific study of animal behaviour.

In reality, conservation project teams rarely include a behavioural expert. And ethologists admit that they are partly to blame. "We missed the bandwagon," says Richard Buchholz of the University of Mississippi in Jackson. "It's our own fault."

At the Animal Behavior Society's annual meeting in July, held in Corvallis, Oregon, Buchholz organized a workshop to address this failing. Participants pointed to numerous conservation projects that have run into trouble for lack of behavioural data - but noted a few resounding successes from the marriage of conservation and ethology.

Paul Sherman, a behavioural ecologist at Cornell University in Ithaca, New York, is one of the few ethologists who has helped to redesign a species recovery plan. In 1985 , he teamed up with his former student Brad Semel to study a phenomenon in wood ducks (Aix sponsa) that conservation managers were calling dump-nesting.

Since the 1930s, managers had been erecting nest boxes on wildlife preserves for wood ducks, which had been hunted to near extinction by the beginning of the twentieth century. Because the birds prefer to nest in tree cavities, it was thought that placing wooden boxes on poles over open marshes would accelerate their recovery.

But many females laid their eggs in the same nest box while other boxes went unclaimed."We had eggs laid on top of boxes,

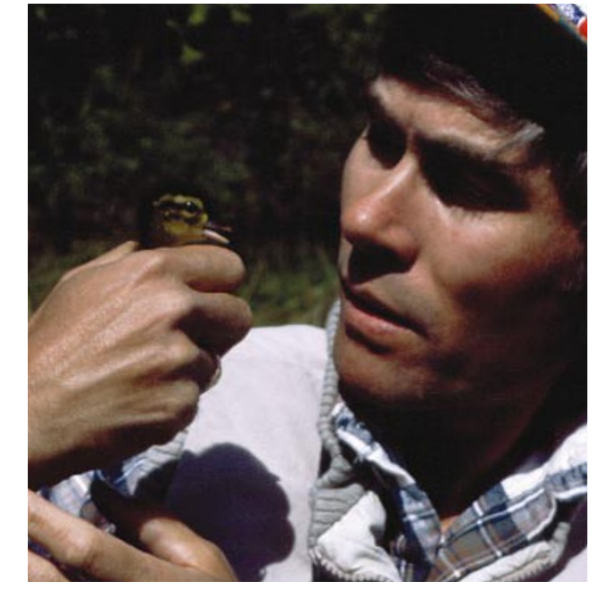

in the water, even on top of other ducks," says Sherman. Some nests were filled with up to 30 eggs, rather than the natural dozen or so. Because females tend to abandon nests that contain too many eggs, hatching success was low, dipping to only $10 \%$ at some sites.

\section{Lame ducks}

Dump-nesting turned out to be related to a natural phenomenon known as brood parasitism. Female wood ducks sometimes leave eggs in other birds' nests to avoid the costs of incubating them. Under normal circumstances, a nest might contain two or three extra eggs deposited in this way.

Through many years of painstaking field observations, Sherman and Semel showed that older ducks usually return to the same nest site year after year. But they found that newcomers, particularly yearlings, seem to rely on seeing adult females entering their nest to find a place to lay their eggs. For them, brood parasitism is the norm. At natural nest sites, which are usually hidden in the woods, this does not place too great a burden on the

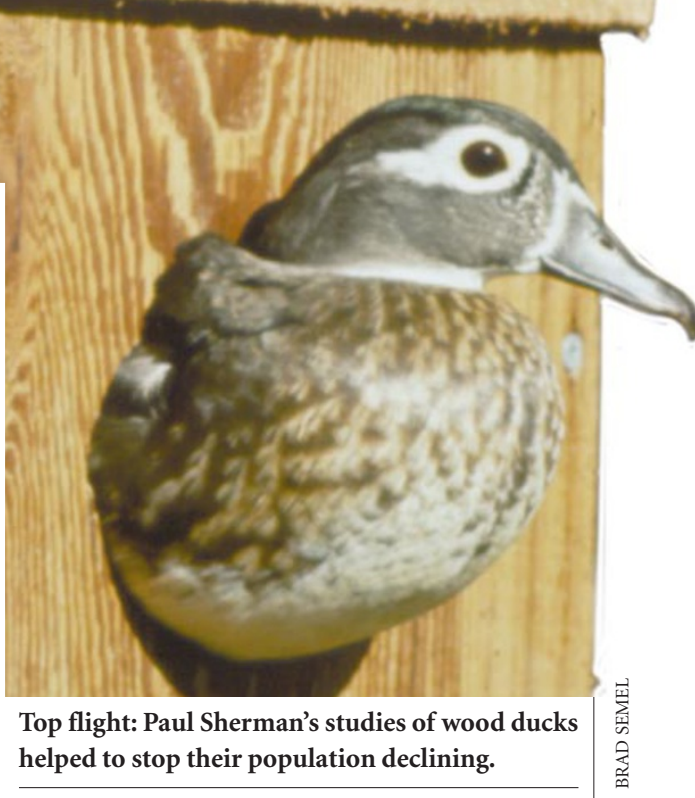

experienced ducks. But Sherman and Semel found that the nest boxes were just too conspicuous: every yearling in the neighbourhood flocked to them ${ }^{1}$.

In response to these findings, conservationists now hide nest boxes in the woods and keep them far apart. Hatching rates among ducks nesting at these sites have soared to more than $70 \%$, much the same as for natural nests ${ }^{2}$.

Unfortunately, says Tim Caro, a behavioural ecologist at the University of California, Davis, the wood duck example is a rare success story. Many ethologists mention the implications of their work for conservation at the end of their papers, but few actually liaise with conservation biologists. "I don't think that it filters through to the decisions being made on the ground," says Caro.

The fact that Sherman and Semel's findings took more than a decade to crystallize illustrates one of the main problems. Conservation projects are often pressed for time and money, says Jim Strittholt, who directs the Conservation Biology Institute, a a 
consultancy based in Corvallis. "Behavioural studies usually take several seasons," he says. "If you have a nine-month project there is no way you can incorporate that."

Politics can also come into play. Some areas of conservation are so politicized that ethologists have a hard time being heard. In North America, for example, environmentalists, anglers, hydroelectric companies and native Americans all fight to influence decisions over salmon conservation.

Yet this example illustrates the vital contribution that ethologists can make. Hatcheries are now reintroducing endangered salmon species to bolster wild populations. But there is evidence that adult salmon raised in captivity have behavioural abnormalities that could affect their reproduction in the wild. They might spawn too early ${ }^{3}$, or too far downstream in the river ${ }^{4}$, or compete less effectively for mates than their wild cousins ${ }^{5}$. And if enough captive-bred fish enter a wild population, the reproductive success of the whole population can drop ${ }^{6}$.

\section{Fishy business}

Other behavioural scientists are concerned about the emphasis on genetic diversity for salmon reintroductions. The general assumption is that greater diversity makes a population more resilient. But Mart Gross, a behavioural biologist at the University of Toronto, is not convinced.

Females of many species choose males on the basis of gene quality, notes Gross. The result is not maximum diversity, but selection of the best genes. Gross argues that hatcheries might produce more robust fish by letting females choose their mates, rather than pairing the fish off according to a diversity protocol. "Our view is that they actually mongrelize their populations," he says.

Although influencing salmon conservation may be challenging, ethologists who talk to policy-makers are finding they can make a difference. William Sutherland, a biologist at the University of East Anglia in Norwich, is one. Recently passed legislation to open the British countryside to the public has raised concerns about the impact on wildlife, so the government is working to make exceptions for sensitive areas. Sutherland uses theoretical models based on the nesting behaviour of birds to predict the effects of human disturbance ${ }^{7}$. The government has asked him to help to identify areas of farmland and open heath in which populations might be particularly vulnerable. The key is to get involved early on, says Sutherland. "If you come in at the end and say 'Why don't you do this?', it can be seen as a criticism."

This is also the approach of Daniel Blumstein, a behavioural biologist at the University of California, Los Angeles, and the Marsupial Cooperative Research Centre (MCRC) in Sydney, who is collaborating with the South Australian government on

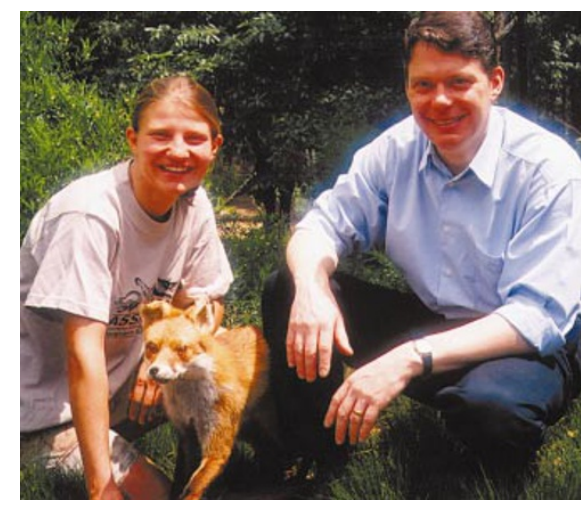

Foxy moves: Andrea Griffin and Chris Evans teach tammar wallabies how to escape predators.

the reintroduction of tammar wallabies (Macropus eugenii). Although tammars are no longer found on the Australian mainland, an introduced population survives in New Zealand - where it has no known predators.

This is a potential problem, as animals raised in the absence of predators may struggle to survive when exposed to nature red in tooth and claw. Many reintroduction programmes have failed because of this ${ }^{8}$. Although predator-avoidance behaviour is in part hard-wired, practice makes perfect. Releasing naïve animals into an environment full of predators can be tantamount to putting them out to die, says Blumstein.

\section{Getting jumpy}

Through the MCRC, Blumstein is collaborating with Andrea Griffin and Chris Evans of Sydney's Macquarie University to train wallabies to avoid predators. In a typical session they place a stuffed fox in the wallaby's enclosure, then five seconds later a researcher tries to grab the animal something wallabies particularly dislike. The researchers have found that the training instils a fear of foxes, which the tammars can generalize to other predators, such as cats ${ }^{9}$.

Whether predator-avoidance training improves an animal's chances of survival has been tested in only a handful of species, with mixed results. Houbara bustards (Chlamydotis undulata macqueenii $)^{10}$ and masked bobwhite quails (Colinus virginianus ridgwayi $)^{11}$ survived longer after training. But Benjamin Beck of the National Zoological Park in

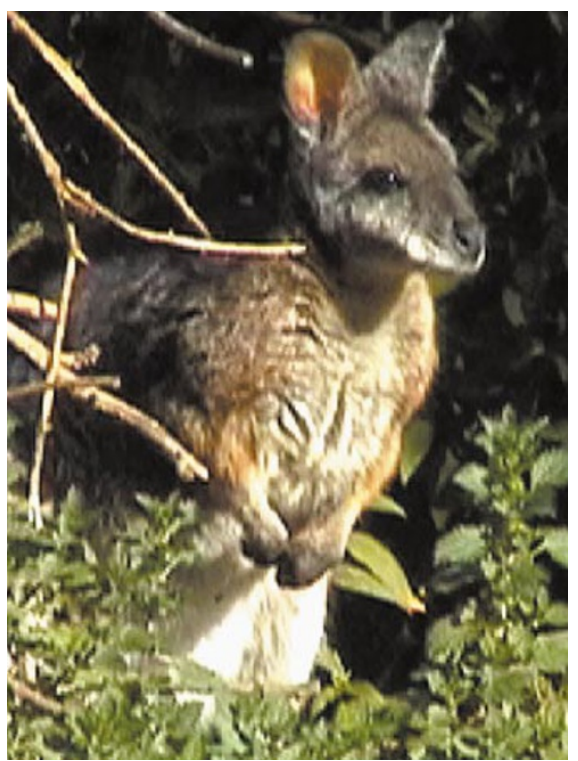

Washington found that it made no difference for golden lion tamarins (Leontopithecus rosalia), an endangered Brazilian primate ${ }^{12}$.

These variable results underline the need to include a behavioural component in conservation projects. And for ethologists, there is an element of self-preservation, as well as species preservation. "Our lives as scientists depend on the availability of organisms in their natural habitats," says Sherman.

Jonathan Knight writes for Nature from San Francisco.

1. Eadie, J., Sherman, P. W. \& Semel, B. in Behavioral Ecology and Conservation Biology (ed. Caro, T.) 306-340 (Oxford Univ. Press, Oxford, 1998).

2. Sherman, P. W. in Model Systems in Behavioral Ecology (ed. Dugatkin, L. A.) 311-337 (Princeton Univ., Princeton, 2001)

3. Nickleson, T. E., Solazzi, M. F. \& Johnson, S. L. Can. J. Fish. Aquat. Sci. 43, 2443-2449 (1986).

4. Jonsson, N., Hansen, L. P. \& Jonsson, B. Anim. Behav. 48, 740-742 (1994).

5. Fleming, I. A. \& Gross, M. R. Ecol. Appl. 3, 230-245 (1993)

6. Fleming, I. A. \& Petersson, E. Nordic J. Freshw. Res. 75, 71-98 (2001).

Gill, J. A., Norris, K. \& Sutherland, W. J. J. Appl. Ecol. 38, 846-856 (2001).

8. Griffin, A., Blumstein, D. T. \& Evans, C. S. Conserv. Biol. 14, 1317-1326 (2000)

9. Griffin, A., Evans, C. S. \& Blumstein, D. T. Anim. Behav. 62, 577-589 (2001).

10. Van Heezik, Y. \& Maloney, R. Re-introduction News 13, 3-4 (1997).

11. Ellis, D. H., Dobrott, S. J. \& Goodwin, J. G. in Endangered Birds: Management Techniques for Preserving Threatened Species

(ed. Temple, S. A.) 345-354 (Univ. Wisconsin, Madison, 1977)

12. Beck, B. B., Castro, M. I., Stoinski, T. S. \& Ballou, J. in The Lion Tamarins: Twenty-five Years of Research and Conservation (eds. Kleiman, D.G. \& Rylands, A) (Smithsonian Institution Press, Washington, in the press)

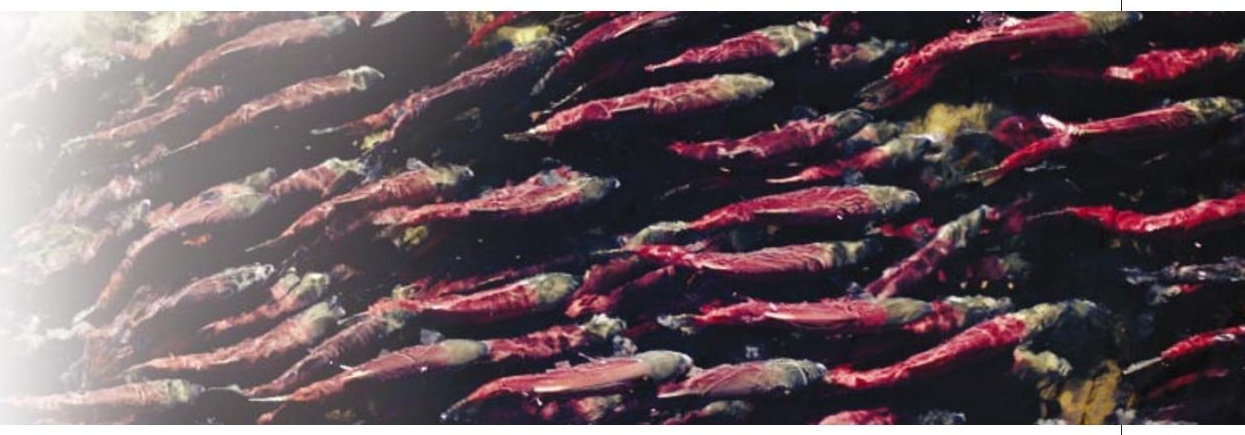

Scaled up: greater genetic diversity isn't necessarily better in fish such as these sockeye salmon. 